Original Paper http://ajol.info/index.php/ijbcs http://indexmedicus.afro.who.int

\title{
Physicochemical properties and fatty acid composition of star fruit (Averrohoa carambola) seed oil
}

\author{
A. E. SAMUEL ${ }^{1 *}$, I. C. NWANKWO ${ }^{2}$, O.O. OLOTU ${ }^{1}$ and I. O. AKINDIYA ${ }^{3}$ \\ ${ }^{1}$ Federal Institute of Industrial Research, Oshodi (FIIRO) Lagos, Nigeria. \\ ${ }^{2}$ Babcock University Ilishan-Remo, Ogun State, Nigeria. \\ ${ }^{3}$ Yaba College of Technology, Yaba, Lagos, Nigeria. \\ ${ }^{*}$ Corresponding author; E-mail: seaadeiza@yahoo.com; Tel: +234-803-242-1643
}

\begin{abstract}
To meet the increasing demands for oil, improvements are being made to produce unique and desirable oils, therefore increasing interest in newer sources of edible oils from natural sources. The physicochemical properties and fatty acid composition of Averrohoa carambola seed oil were determined. Physicochemical properties were determined using standard techniques and the fatty acid profile was obtained using Gas Chromatography Mass Spectroscopy (GC-MS). Soxhlet extraction (using petroleum ether) of the oil from sundried and crushed seeds of Averrohoa carambola gave light yellow oil with a yield of $28.45 \%$ oil per $100 \mathrm{~g}$ of the seeds. Other physicochemical properties of the oil determined were as follows; moisture content (7.2\%), specific gravity (0.705), refractive index (1.421), acid value (0.68), free fatty acid $(0.84)$, iodine value $(140.50$

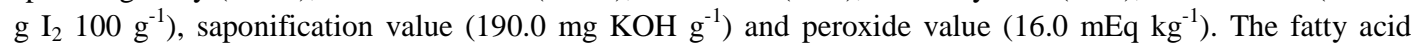
profiles were revealed using Gas Chromatography Mass Spectroscopy (GC-MS). Linoleic (36.01\%) and oleic $(34.05 \%)$ were detected as the major fatty acid while palmitic $(6.75 \%)$ and stearic acid $(3.09 \%)$ were the saturated acid found in the oil. The compositions of the saturated fatty acids (SAFAs), monounsaturated fatty acids (MUFAs) and polyunsaturated fatty acids (PUFAs) were found to be 10.43, 34.44 and $51.98 \%$ respectively. Hence, the oil has a relatively high percentage of unsaturated fatty acid $(86.42 \%)$. The outcome of this study showed that Averrohoa carambola seed oil may find wider industrial application and could be a nutriceutical resource or functional foods ingredient. Hence, the oil may be edible subject to toxicological test. (C) 2016 International Formulae Group. All rights reserved.
\end{abstract}

Keywords: Characterization, levels, saturated, monounsaturated, polyunsaturated, standard techniques.

\section{INTRODUCTION}

Averrhoa carambola, generally called star fruit, is a woody tree plant belonging to the genus Averrhoa and family Oxalidaceae. It is a slow growing; short trunked tree with much branched, bushy, broad, round crown which reaches up to 6-9 $\mathrm{m}$ in height. The fruit is greenish when small and turns yellow or orange when ripe. The fruit is fleshy, fine lobed, ovate to ellipsoid that ranges from 5-8 $\mathrm{cm}$ long and $9 \mathrm{~cm}$ wide. The skin is thin, light to dark yellow and smooth with a waxy cuticle. The fruit is crunchy, and has a slightly tart, acidic, sweet taste, reminiscent of pears and apples. The flesh is light yellow to yellow, translucent, crisp and very juicy 
without fibre. The fruit contains no more than five to eight seeds. It is edible, $0.8-1.5 \mathrm{~cm}$ long, thin, light brown and enclosed by a gelatinous aril. Ripe star fruit can be eaten directly, sliced and served as salads or used to garnish seafood's (Tidbury et al., 1976).

Globally, as a result of expanding population and rapid industrialization, there has been growing demand for vegetable oil, much interest is now focused on exploring non-conventional bioresource plant for oil production (Anhwange, 2004). New oil seeds with nutritional and pharmaceutical values have been rapidly explored decades ago. The food and agricultural organization of the United Nations (FAO) defines oil-bearing crops to include both annual (usually oil seeds) and perennial plant whose seeds, fruits or mesocarp and nuts are valued mainly for the edible or industrial oils that can be extracted. The FAO listed twenty-one oil crops, with an annual world oil seed production approximately two million metric tons (Foreign Agricultural Service USA, 2014). Production of soybean dominates the industry, with cotton seed, peanut, sunflower and rapeseed/canola as other significant contributors.

Oilseeds crops are generally grown for purpose of oil in the seeds and they vary considerably in their oil content, quality and composition. These factors rely heavily on the crop species or cultivars and upon the environmental conditions in which the crop is grown (Mailer, 2004). A large quantity of oil and fats, whether for human consumption or for industrial purposes is presently derived from plant sources (Ramadan et al., 2006). Plant seeds are important sources of oils of nutritional, industrial and pharmaceutical significance (Ramadan et al., 2006).

No oil from any source has been found to be suitable for all purposes because oils from different sources generally differ in their composition (Dubois et al., 2007). This necessitates the search for new sources of novel oils, of which several plants are now grown not only for food and fodder, but also for a striking variety of products with applications in industry, including essential oils and pharmaceuticals (Aremu et al., 2006b).Vegetable oil not only provides high quality food, containing essential nutrients for life, but also bestows bioactive compounds that have particular clinical significance (Mehmood et al., 2008). The advent of alternative vegetable oil production has also triggered the insatiable search for alternative sources of raw material for this purpose. More, so there could be a variable chemical composition depending on several factors such as the cultivation environment (Ixtaina et al., 2011).

Currently, to the best of our knowledge, no data exist for the detailed physicochemical characteristics and fatty acid composition of seed oil from Averrohoa carambola. Therefore, this study was aimed at characterizing the seed oil from Averrohoa carambola to meet the ever- increasing demand for oils and their quality for food, industrial and pharmaceutical applications.

\section{MATERIALS AND METHODS \\ Collection and preparation of Averrohoa carambola seeds \\ The fruits of Averrohoa carambola} were collected within the Federal Institute of Industrial Research, Oshodi, South-West Nigeria. The fruits were manually squeezed to expel the seeds, whose voucher was identified by a Botanist. They were washed with water, sun-dried for two weeks; the seeds were decorticated manually, washed and dried in an oven at $40{ }^{\circ} \mathrm{C}$ for six hours, and milled into powder with a previously cleaned blender (Binatone, Japan, model BLG-400).

\section{Extraction of Averrohoa carambola seed oil and its percentage yield}

Oil was extracted from the paste with petroleum ether $\left(40-60{ }^{\circ} \mathrm{C}\right)$ using soxhlet extraction method (Eromosele et al., 1994). $100 \mathrm{~g}$ of ground Averrohoa carambola seeds were packed in a soxhlet thimble and $500 \mathrm{ml}$ solvent (petroleum ether) was poured into the $1000 \mathrm{ml}$ soxhlet round bottom distillation flask. A condenser was connected to the top of 
the extractor. The heating mantle was switched on (set at $50{ }^{\circ} \mathrm{C}$ ) and heat was supplied to the distillation flask. Vaporized solvent were generated and condensed as hot liquid solvent in the packed thimble. This process continued for 3 hours and resulted in the extraction of the oil through various siphoning of oil plus solvent into the distillation flask. The mixture of oil and solvent was separated by the use of rotary evaporator. The percentage oil yield was computed using the equation

$\%$ oil yield $=\left[\mathrm{M}_{2} / \mathrm{M}_{1}\right] \times 100$

Where $\mathrm{M}_{1}$ and $\mathrm{M}_{2}$ are mass of Averrohoa carambola seed packed into soxhlet thimble and mass of recovered oil from rotary evaporator respectively.

\section{Determination of the physicochemical properties of Averrohoa carambola seed oil}

The physicochemical properties (moisture content, iodine value, saponification index, peroxide value, refractive index, free fatty acid, acid value, colour and specific gravity) were measured using the American Oils Chemists Society Methods (AOCS, 1996).

\section{Determination of moisture content}

Two grams of oil sample was weighed into a cleaned dried weighed crucible. This was dried in an oven set at 105 ${ }^{\circ} \mathrm{C}$ for 2 hours. The moisture content was calculated thus:

$\%$ Moisture Content $=[(\mathrm{B}-\mathrm{D}) / \mathrm{B})] \times 100$

Where $B$ is weight of oil sample before drying and D is the weight of oil sample after drying.

\section{Determination of specific gravity}

The specific gravity of the oil sample was determined employing the weight ratio of the oil to the equivalent weight of water according to the following equation: Specific gravity $(\mathrm{SG})=\mathrm{W}_{3}-\mathrm{W}_{2} / \mathrm{W}_{1}$ Where $\mathrm{W}_{1}, \mathrm{~W}_{2}$ and $\mathrm{W}_{3}$ are the respective weights equivalents of water, empty bottle and oil sample.
Determination acid value and free fatty acid

A mixture of $25 \mathrm{ml}$ diethyl ether with $25 \mathrm{ml}$ of ethanol and $1 \mathrm{ml} 1 \%$ phenolphthalein solution contained in a $250 \mathrm{ml}$ conical flask was carefully neutralized with $0.1 \mathrm{M} \mathrm{KOH}$ (blank titration), A $0.1 \mathrm{M} \mathrm{KOH}$ solution was used to titrate $2.0 \mathrm{~g}$ of the solvent homogenized oil $(25 \mathrm{ml}$ diethyl ether $+25 \mathrm{ml}$ ethanol $+1 \mathrm{ml} 1 \%$ phenolphthalein $+2.0 \mathrm{~g}$ ), with constant agitation until the content of the flask turns pink. The acid value (AV) and free fatty acid (FFA) were computed as follows:

$\mathrm{AV}=[(\mathrm{B}-\mathrm{V}) \times \mathrm{N} \times 56.1] / \mathrm{W}$

$\mathrm{FFA}=[(\mathrm{B}-\mathrm{V}) \times \mathrm{N} \times 28.2] / \mathrm{W}$

$\mathrm{B}$ is the volume of $\mathrm{KOH}$ for blank titre $(\mathrm{ml})$, $\mathrm{V}$ is the volume of $\mathrm{KOH}$ for sample titre $(\mathrm{ml})$, $\mathrm{N}$ (Normality) of $\mathrm{KOH}$ solution and $\mathrm{W}$ is the weight of oil sample.

\section{Determination of iodine value}

$10 \mathrm{ml}$ of $15 \% \mathrm{KOH}$ was aggregated to $2.0 \mathrm{~g}$ of oil sample contained in a $250 \mathrm{ml}$ conical flask. 30 milliliters of Hanus reagent mixture that was stationed initially for 30 minutes in a cupboard was also added. The resulting solution was titrated with $0.12 \mathrm{M}$ $\mathrm{Na}_{2} \mathrm{~S}_{2} \mathrm{O}_{3}$. Titration was also carried out for the blank. The equation below was used to evaluate the iodine value (IV).

$\mathrm{IV}=\left[(\mathrm{B}-\mathrm{V}) \times\right.$ molarity of $\times \mathrm{Na}_{2} \mathrm{~S}_{2} \mathrm{O}_{3}$ $(0.3 \times 12.69)] / \mathrm{W}$

$\mathrm{B}$ is the volume of blank titre $(\mathrm{ml}), \mathrm{V}$ is the volume of sample titre $(\mathrm{ml})$ and $\mathrm{W}$ is the weight of oil sample

\section{Determination of saponification value}

$2.0 \mathrm{~g}$ of oil sample was measured into a $250 \mathrm{ml}$ initially containing $25 \mathrm{ml}$ of ethanolpotassium hydroxide solution. The flask was fitted with a condensing set-up and solution was refluxed for 30 minutes. The solution was titrated while still hot against $1 \mathrm{M} \mathrm{H}_{2} \mathrm{SO}_{4}$ and the test titre value recorded. Similar procedure was followed for the blank (without oil sample) determination. The difference between the blank and the test titre values gives the amount of $\mathrm{KOH}$ absorbed by the oil. Saponification value $=\left[28.05\left(\mathrm{~V}_{1}-\mathrm{V}_{2}\right)\right] / \mathrm{W}$ 


\section{Determination of peroxide value}

$1.0 \mathrm{~g}$ of oil sample was weight into a conical flask after which a mixture of glacial acetic acid and chloroform was added in a ratio of $3: 2 \mathrm{v} / \mathrm{v} .0 .5 \mathrm{ml}$ of saturated potassium iodide was added and flask swirled for 2 minutes, $30 \mathrm{ml}$ distilled water was added to the resultant orange mixture. $0.5 \mathrm{ml}$ starch indicator was added and the titration continued until the blue colour formed disappeared. The flask and its content were shaken near the end-point to ensure that all the iodine was liberated from the chloroform layer. The blank was carried out in a similar manner without the oil sample.

Peroxide value $(\mathrm{PV})=\left[\mathrm{M}\left(\mathrm{V}_{\mathrm{b}-} \mathrm{V}_{\mathrm{s}}\right)\right] / \mathrm{W} \times 100$ Where $\mathrm{V}_{\mathrm{s}}=$ volume of the $\mathrm{Na}_{2} \mathrm{~S}_{2} \mathrm{O}_{3}$ (test titre), $\mathrm{V}_{\mathrm{b}}=$ volume of blank titre, $\mathrm{M}=$ molarity of $\mathrm{Na}_{2} \mathrm{~S}_{2} \mathrm{O}_{3}, \mathrm{~W}=$ weight of oil sample.

\section{Determination of refractive index}

The instrument (refractometer) consists of double prism, a telescope and a scale for reading the refractive index. The glass prism (with known index) was cleaned with cotton wool soaked in ethanol. The sample oil was then dropped on the surface of the lower glass prism and closed. The monochromatic light ray was passed through the glass prism and produced an image in the observing telescope which was focused at the direction of the refracted ray. The prism box was adjusted until the two sections were observed. i.e. an illumination part and dark part. The box was adjusted continuously until the boundary between the illuminated and the dark area of the field became sharp. The refractive index was then read of on the scale through the eyepiece.

Determination of fatty acid composition of Averrohoa carambola seed oil

The fatty acid composition was determined as fatty acid methyl esters (FAMEs), according to the method as outlined by Haiyan et al. (2007). $0.2 \mathrm{ml}$ of methanolic potassium hydroxide $(0.2 \mathrm{M})$ was added to 0.1 $\mathrm{g}$ oil in $2.0 \mathrm{ml} \mathrm{n}$-heptane. The mixture was shaken vigorously and allowed to stand and separate. An aliquot $(1.0 \mathrm{ml})$ of the heptane phase was removed and dissolved in a further $1.0 \mathrm{ml} \mathrm{n}$-heptane. Separation of fatty acids esters was performed on a Gas Chromatography (SHIMADZU GCMS-QP 2010). The analyte $(1 \mu l)$ was injected into the column. The Gas Chromatography program includes raising oven temperature to $280{ }^{\circ} \mathrm{C}$ from ambient temperature using $10^{\circ} \mathrm{C} / \mathrm{min}$. ramping rate. The initial and final column temperature was held for 0 and 5 minutes, respectively. The injector temperature was carefully programmed to $250{ }^{\circ} \mathrm{C}$. The identification of the unknown FAMEs was based on the similarity search performed using NIST 2005 library on the basis of the peak areas by a chromatography GCMS solution for SHIMADZU GCMS-QP 2010 data handling program.

\section{RESULTS AND DISCUSSION \\ Physicochemical properties}

Table 1 presents the physicochemical characteristics of Averrohoa carambola seed oil compared with other seed oils. The oil was light yellow in colour and compares very well with that obtained from linseed oil (Majunder, 1990). Lighter colored oils are important from a technical view-point, indicating that Averrohoa carambola seed oil could be more acceptable as edible oil or for other oleochemical processes after slight bleaching, owing to the low amount of coloring (chlorophyll and carotenoids) matters/pigments extracted alongside with the oil.

The oil yield $(28.45 \%)$ is higher than $18.30-21.53 \%$ oil yield reported for various soybean cultivars (Vasconcelos et al., 1997) and lower than $45.71 \%$ for Ximenia americana seed oil (Eromosele et al., 1994) and castor seed oil $44.69 \%$ (Onukwli and Igbokwe, 2008), suggesting the classifying of Averrohoa carambola plant as an oilseed plant. The iodine value of the oil was $140.50 \mathrm{~g}$ $\mathrm{I}_{2} 100 \mathrm{~g}^{-1}$ this value compares very well with that of rubber seed oil $136.20 \mathrm{~g} \mathrm{I}_{2} \quad 100 \mathrm{~g}^{-1}$ (Ikhuoria and Okieimen, 2005). 
According to Eromosele et al. (1994) this places the seed oil of Averrohoa carambola as semi-drying oil and could be used in the synthesis of alkyd resin for paint formulation and chemically modified monomer for the polymer industry. The iodine value also indicates better combustible properties, which lay credence to the oil as a potential raw material in the biodiesel industry (Adebayo et al., 2011). The iodine value (140.50 $\mathrm{g} \mathrm{I}_{2} 100 \mathrm{~g}^{-1}$ ) obtained in this study indicates that the oil contain, appreciable level of unsaturation. Hence, storage procedure to be used for this oil should ensure protection of the oil from oxidative deterioration. The low acid value $\left(0.68 \mathrm{mg} \mathrm{KOH} \mathrm{g}^{-1}\right)$, compares well with $0.82 \mathrm{mg} \mathrm{KOH} \mathrm{g}^{-1}$ reported for cashew nut oil (Aremu et al., 2006b). The low free fatty acid $(0.846 \%)$, coupled with its low acid value $\left(0.68 \mathrm{mg} \mathrm{KOH} \mathrm{g}^{-1}\right)$, suggest low lipolytic activities in the oil, it presents the oil as edible and industrially useful (Aremu et al., 2006b; Razip et al., 2012).

The nutritional value of fat or oil largely depends on the amount of free fatty acids (e.g. butyric acid in butter) which develops (Ajayi et al., 2006). In the tropics, where vegetable oils are the most common dietary lipids, it is desirable to ensure that the free acid contents of cooking oils lie within limits of $0.3-1.3 \%$ (Ajayi et al., 2006). Free fatty acid can stimulate oxidative deterioration of oils by enzymatic and/or chemical oxidation to form off-flavor components. Free fatty acid is also related to smoke point. Hence, the low free fatty acid of Averrohoa carambola seed oil laid claim to Averrohoa carambola seed oil as a good candidate for stir-frying.

The saponification index of Averrohoa carambola oil is $190.0 \mathrm{mg} \mathrm{KOH} \mathrm{g}^{-1}$ and it is higher when compared with values for Ximenia americana seed oil, Rubber seed oil, Castor seed oil and linseed oil; 178.50, $181.14,182.14$ and $185.0 \mathrm{mg} \mathrm{KOH} \mathrm{g} \mathrm{g}^{-1}$ respectively. This suggests that Averrohoa carambola seed oil may contain high proportion of short-chain fatty acids (Eromosele and Pascal, 2003). Thus, the oil may be suitable for the preparation of liquid soap and hair shampoo.

The peroxide value of $16 \mathrm{mEqkg}^{-1}$ which is lower than $31.25 \mathrm{mEqkg}^{-1}$ for Ximenia americana seed oil, but higher compared to $6.7 \mathrm{mEqkg}^{-1}$ for Castor seed oil, suggest the oil stability to oxidative rancidity. This may also point to the presence of natural antioxidants such as $\alpha$-tocopherol and tocotrinol in the oil which provides stability during packaging and storage (Eromosele et al., 1994).

The refractive index of the oil at $30{ }^{\circ} \mathrm{C}$ was 1.421. This value is comparable with Lophira lanceolata; 1.459, Haemotostaphis beteri; 1.460 and Cyperus esculentus; 1.451 (Eromosele et al., 1994). In addition, the refractive index is also comparable with edible oils such as palm oil; 1.457, groundnut oil; 1.458-1.466 and cotton seed oil; 1.401.465 (Rangana, 1986). The refractive index also revealed that Averrohoa carambola seed oil contained some double bonds in its fatty acid composition (Dubois et al., 2007). This indicates that the seed oil have high proportion of unsaturated fatty acids and suggest that the seed oil could be useful in formation of alkyd resin for paints and in the preparation of oil creams. The low specific gravity $\left(0.705 \mathrm{gcm}^{-3}\right)$ and low moisture content (7.2\%) of Averrohoa carambola seed oil implies good shelf-life characteristics.

\section{Fatty acid composition}

Table 2 shows the fatty acid composition of Averrohoa carambola seed oil. Saturated, Monousaturated and Polyunsaturated fatty acids constituted nearly $10.43,34.44$ and $51.98 \%$ respectively. The unknown fatty acid content was $2.99 \%$. linoleic $(36.01 \%)$ and oleic $(34.05 \%)$ acids were the principal fatty acids. The content of oleic acid in this analysis was found to be lower compared to $(72.09 \%)$ for Ximenia americana seed oil (Eromosele and Eromosele, 2002), but higher compared to (20.2-23.0\%) reported for four watermelon varieties in Pakistan (Razip et al., 2012). 
The linoleic acid content for Averrohoa carambola seed oil (36.01\%) was appreciably higher in comparison to $(1.34 \%)$ found for Ximenia americana seed oil (Eromosele and Eromosele, 2002). The promising amount of linoleic acid entails disease curing potentials and also presents cardiovascular linear option for other oils (Aremu et al., 2006b). Similarly, adequate concentration of omega-6 ( linoleic acid $36.01 \%$ ) is also indicating a potentially useful food additive and be converted to gamma-linoleic acid that can be used as a dietary increment to surge the production of anti-inflamatory 1-series prostaglandins. Series 1-prostaglandins play a crucial role in controlling blood thickness and blood pressure (Eromosele and Pascal, 2003).

The total (MUFA + PUFA) content of unsaturated fatty acid $(86.42 \%)$ compares well with that found for watermelon seeds $(81.6 \%)$ ( Baboli and Kordi, 2010). It is also similar and in levels from five melon species (67.93$82.36 \%$ ) (Mabaleha et al., 2007). Thus, the oil from Averrohoa carambola seed can be regarded as linoleic-oleic oil. The high amount of total unsaturated fatty acid $(86.42 \%)$ shows that the oil is suitable for edible cooking or as salad oils and for manufacture of margarine (Haiyan et al., 2007). Other essential fatty acid detected in this oil was arachidic and behenic acids with relatively low concentrations of $0.28 \%$ and $0.15 \%$ respectively.

Due to its physical properties, addition of behenic acid can lighten chocolate texture and oily feel (Matsui et al., 2000) and provide excellent mouth-feel and melt-down behavior to semi-solid and solid fats such as margarine, shortening and foods containing semi-solid and solid fats (Cain and Moore, 1995). Also behenic acid is poorly absorbed from the diet and can be used in low calorie foods (Lalas and Tsakins, 2002). Non food uses of behenic acid include applications as surfactants and detergents, plastics, cosmetics, photographing and recording materials (Sonntag, 1991).

The total quantity of saturated fatty acids (SAFA) $10.434 \%$ present is lower compared to values (14.3-16.2\%) obtained from four watermelon varieties in Pakistan by (Razip et al., 2012). These values were also lower compared to (17.8\%) for Citrullus lanatus (Ziyada and Elhaussien, 2007) and (12-36\%) reported for different species of musk melon seed oils (Tilak et al., 2006). This makes the oil from Averrohoa carambola seeds, suitable for diet low in saturates which is beneficial to patients with cardiovascular disorders (Nicolosi et al., 2004).

An important fatty acid characteristic of Averrohoa carambola seed oil is a relatively high level of polyunsaturated fatty acids (PUFAs). PUFAs especially omega-6 such as; linoliec acid (LA), gamma-linolenic acid (GLA) and omega-3 acids such as; alphalinolenic acid (ALA) were found in this study. The oil showed a significant percentage of ALA (15.87\%) sharing this specialty with seed oils such as blackcurrant seed oil (12$14 \%)$, gooseberry seed oil (19-20\%) and redcurrant seed oil (21-29\%) (Trailer et al., 1988), and commercial seed oils such as soybean oil $(5.5-9.5 \%)$ and canola oil (8-10\%) (Gunstone et al., 1994). Due to the inability of human body to synthesize these fatty acids, PUFAs such as LA, ALA and GLA are obtained from vegetable oils.

The importance of LA and ALA in human diet had been highlighted (Kuresh et al., 1999). These fatty acids are derived through a series of desaturation and elongation to form longer and more unsaturated fatty acids (Shahidi and Wanasundara, 1998; Yung et al., 2004). The level of GLA in Averrohoa carambola seed oil is low, but could contribute significantly to PUFA level of this oil. The interest in PUFAs generally has expanded rapidly because of its benefits in alleviating cardiovascular, inflammatory conditions, heart disease, atherosclerosis, autoimmune disorders, diabetes and other diseases (Ramadan et al., 2006). The low saturated fatty acid content and high level of polyunsaturated fatty acids qualify Averrohoa carambola seed oil as a good source of nutritionally essential fatty acids and as a special component for functional foods low in saturates. 
Table 1: Physicochemical properties of Averrohoa carambola seed oil (ACSO) compared with rubber seed oil, castor seed oil, linseed oil and Ximenia americana seed oil (XASO).

\begin{tabular}{|c|c|c|c|c|c|}
\hline Properties & ACSO & $\begin{array}{l}\begin{array}{l}\text { Rubber } \\
\text { seed oil }^{\mathrm{a}}\end{array} \\
\end{array}$ & $\begin{array}{c}\begin{array}{c}\text { Castor } \\
\text { seed oil }^{\mathrm{b}}\end{array} \\
\end{array}$ & $\begin{array}{c}\text { linseed } \\
\text { oil }^{\mathbf{c}}\end{array}$ & XASO $^{d}$ \\
\hline Colour & Light Yellow & Brown & - & Yellow & Dark Brown \\
\hline Moisture content (\%) & 7.2 & - & - & - & - \\
\hline Oil yield (\%) & 28.45 & - & 44.67 & - & 45.7 \\
\hline Specific gravity $\left(\mathrm{gcm}^{-3} @ 30^{0} \mathrm{C}\right)$ & 0.705 & 0.93 & 0.93 & 0.98 & 0.912 \\
\hline Refractive index (@30 & 1.421 & 1.477 & - & 1.48 & 1.467 \\
\hline Acid value $\left(\mathrm{mg} \mathrm{KOH} \mathrm{g}^{-1}\right)$ & 0.68 & 19.18 & 2.89 & 1.0 & 16.13 \\
\hline Free fatty acid (\%) & 0.846 & 9.54 & 1.45 & - & 8.07 \\
\hline Iodine value $\left(\mathrm{g} \mathrm{I}_{2} 100 \mathrm{~g}^{-1}\right)$ & 140.50 & 136.2 & 82.8 & 188.0 & 152.28 \\
\hline Saponification index $\left(\mathrm{mg} \mathrm{KOH} \mathrm{g}^{-1}\right)$ & 190.0 & 181.14 & 182.0 & 185.0 & 178.5 \\
\hline Peroxide value $\left(\mathrm{mEqkg}^{-1}\right)$ & 16.0 & - & 6.7 & - & 31.25 \\
\hline
\end{tabular}

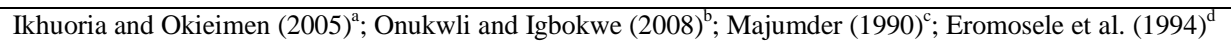

Table 2: Fatty acid composition of Averrohoa carambola seed oil.

\begin{tabular}{lc}
\hline Fatty acid & Composition (\%) \\
\hline Saturated fatty acids (SAFAs) & \\
Caprylic & 0.027 \\
Lauric & 0.142 \\
Myristic & 0.004 \\
Palmitic & 6.751 \\
Stearic & 3.085 \\
Arachidic & 0.276 \\
Behenic & 0.149 \\
Total SAFA & $\mathbf{1 0 . 4 3 4}$ \\
\hline Monounsaturated fatty acids (MUFAs) & \\
Palmitoleic & 0.025 \\
Oleic & 34.051 \\
Gadoleic & 0.132 \\
a-oleic & 0.182 \\
Total MUFA & $\mathbf{3 4 . 4 4}$ \\
\hline Polyunsaturated fatty acids (PUFAs) & \\
Linoleic & 36.01 \\
a-linolenic & 15.862 \\
$\delta$ - linolenic & 0.106 \\
Total PUFA & $\mathbf{5 1 . 9 7 8}$ \\
\hline Unknown fatty acids & $\mathbf{2 . 9 8 5}$ \\
\hline
\end{tabular}

\section{Conclusion}

The result from this study has provided detailed information on the physical and chemical characteristics, as well as fatty acid profile of Averrohoa carambola seed oil. It was also revealed that the oil is linoleic-oleic and could find wide application for human consumption, pharmaceuticals and oleochemical processes. In addition, the 
absence of erucic acid invites attention for its importance as nutriceutical.

\section{COMPETING INTEREST}

The authors declare that they have no competing interests.

\section{AUTHORS' CONTRIBUTIONS}

AES, IOA and OOO did the collection and pretreatment of star fruit (Averrohoa carambola) seeds. AES, ICN and IOA designed and executed the experimental protocols for determination of physicochemical properties of Averrohoa carambola seed oil. ICN, OOO and AES performed the gas chromatography/mass spectroscopy (GC-MS) analysis of sample oil for fatty acid profile and interpretation of data. AES and ICN prepared the manuscript.

\section{ACKNOWLEDGEMENTS}

The authors are grateful and wish to appreciate the Analytical Division of the Federal Institute of Industrial Research, Oshodi Lagos-Nigeria for technical assistance and for provision of research facilities.

\section{REFERENCES}

Adebayo GB, Ameen OM, Abass LT. 2011. Physico-chemical properties of biodiesel produced from Jatropha Curcas oil and fossil diesel. $J$. Microbiol. Biotech. Res., 1(1): 12-16. DOI: http://dx.doi.org/10.4014/jmb. 1502.02034.

Ajayi LA, Oderinde RA, Kajogbola DO, Uponi JI. 2006. Oil content and fatty acid composition of some underutilized legumes from Nigeria. Food Chemistry, 99: 115-120. DOI: http://dx.doi.org/ 10.1016/j.foodchem.2005.06.045

Anhwange BA, Ajibola VO, Oniye SJ. 2004. Chemical studies of the seeds of Moringa oleifera (Lam) and Detarium microcarpum (Guill and Sperr). J. Biol. Sci., 4(6): 711-715. DOI: http://dx.doi.org/10.7150/ijbs. 12852

AOCS. 1996. Sampling and analysis of commercial fat and triglycerides.
Official methods of analysis of the American Triglyceride Chemist Society, pp. 801-855.

Aremu MO, Olonisakin A, Bako DA, Madu PC. 2006b. Compositional studies and physicochemical characteristics of Cashew Nut (Anarcadium occidentale) Flour. Pak. J. Nutr. 5(4): 328-333.

Baboli ZM, Kordi AAS. 2010. Characteristics and composition of watermelon seed oil and solvent extraction parameters effects. J. Am. Oil Chem. Soc., 87: 667671. DOI: http://dx.doi.org/10. 1021/jacs.2009.04.019

Cain FW, Moore SR. 1996. Behenic-rich triglycerides. United States Patent No. 5: 654-1018.

Dubios V, Breton S, Linder M, Fanni J, Parmentier M. 2007. Fatty acid profile of eighty vegetable oils with regard to their nutritional potential. European Journal of Lipid Science and Technology, 109: 710-732. DOI: http://dx.doi.org/10.1002/ejlt.20070004 0

Eromosele CO, Eromosele IC. 2002. Fatty acid compositions of seed oil of Haematostaphis barteri and Ximenia americana. Bioresouces Technol., 80: 303-304. DOI: http://dx.doi.org/10. 1016/S0960-8524(01)00179-1

Eromosele CO, Pascal NH. 2003. Characterization and viscosity parameters of seed oils from wild plants. J. Bioresour. Technol., 86: 203205.

Eromosele IC, Eromosele CO, Akinloye AO, Komolafe FO. 1994. Characterization of oils and chemical analyses of seeds of wild plants. Plant Foods Hum. Nutr., 46: 361-365. DOI: http://dx.doi.org/ 10.1007/BF01088437

Foreign Agricultural Service USDA. 2014. Major Vegetable oils: World Supply and Distribution. http://www.fas. usda.gov.oilseeds/circular/2014.

Gunstone FD, John LH, Fred BP. 1999. The Lipid Handbook (2nd edn). Chapman 
and Hall Chemical Database: US; 185206.

Haiyan Z, Bedgood DR, Bishop AG, Prenzler PD, Robards K. 2007. Endogeneous biophenol, fatty acid and volatile profiles of selected oils. Food Chemistry, 100: 1544-1551. DOI: http://dx.doi.org/10.1016/j.foodchem.2 006.10.050

Ikhuoria EU, Okieimen FE. 2005. Preparation and characterization of alkyd resins using crude and refined rubber seed oil. J. Sci. Ind. Res., 48: 68-73. DOI: http://dx.doi.org/10.3329/bjsirv50i4.25836

Ixtaina VY, Martinez ML, Spotorno V, Mateo CM, Maestri DM, Diehl BWK, Tomas MC. 2011. Characterization of Chia seed oils obtained by pressing and solvent extraction. Journal of Food Composition and Analysis, 24(2): 166174. DOI: http://dx.doi.org/10. 1016/j.jfca.2010.08.006

Kuresh AY, Antnio M, James AJ. 1999. Essential fatty acid the brain; the brain possible health implications. Int. J. Neurosci., 18: 383-399. DOI: http://dx.doi.org/10.3109/00207454.19 98.1136825

Lalas S, Tsakins J. 2002. Characterization of Moringa oleifera seed oil variety "peryakulam1". J. Food Composition Anal., 15: 65-77. DOI: http://dx.doi.org/10.1016/j.jfca.2001.08 .006

Mabaleha MB, Mitei YC, Yeboah SO. 2007. A comparative study of the properties of selected melon seed oils as potential candidates for development into commercial edible vegetable oils. $J$. Am. Oil Chem. Soc., 84: 31-36. DOI: http://dx.doi.org/10.1021/jacs.2006.06. 014

Mailer RJ. 2004. Oilseeds Review. Encyclopedia of Grain Science. pp. 380-386.

Majumder MMUH. 1990. Studies of the physicochemical properties of rubber (Hevea brasiliensis) seed oil and identification of different higher fatty acids of the oil and analysis of the seed cake. Science, 14: 31-36. DOI: http://dx.doi.org/10.1126/science.1989. 05.017

Manzoor M, Anwar F, Iqbal T, Bhanger MI. 2007. Physicochemical characterization of Moringa concanensis seed and seed oil. J. Am. Oil Chem. Soc., 84: 413-419. DOI:http://dx.doi.org/10.1021/jacs.200 6.09.005

Matsui M, Okochi M, Kida H. 2006. Foamed chocolate process for producing the same PCT patent Application No. Wooo-57715.

Mehmood S, Orhan I, Ahsan Z, Aslan S, Gulfraz M. 2008. Fatty acids composition of seed oil of different sorghum bicolor varieties. Food Chemistry, 109(4): 855-859. DOI: http://dx.doi.org/10.1016/j.foodchem.2 008.01 .014

Mortan JF. 1987. Fruits of Warm Climates Miami, FL: Flair Books: Miami; 125.

Nicolosi RJ, Woolfrey B, Wilson TA, Scollin P, Handelman G, Fisher R. 2004. Decreased aortic early atherosclerosis and associated risk factors in hypercholesterolemic hamsters fed high or mid-oleic acid oil compared to highlinoleic acid oil. J. Nutri. Biochem., 15: 540-547. DOI: http://dx.doi.org/ 10.1016/j.jnutbio.2003.08.003

Onukwli OD, Igbokwe PK. 2008. Production and characterization of castor oilmodified alkyd resins. J. Eng. Appl. Sci., 3: 161-165. DOI: http://dx.doi.org/10.3844/ajessp.2007.0 22.003

Ramadan MF, Sharanabasappa G, Seetharam YN, Seshagiri M, Moresel JT. 2006. Characterization of fatty acids and bioactive compounds of Kachnar (Bauhinia purpurea L.) seed oil. Food Chemistry, 98(2): 359-365. DOI: http://dx.doi.org/10.1016/j.foodchem.2 005.06 .018

Rangana S. 1986. Hand Book of analysis and Quality Control for Fruits and 
Vegetable Products (2nd edn). McGraw-Hill Company: New York ; 105-211.

Razip S, Anwar F, Mahmood Z, Shahid SA, Nadeem R. 2012. Characterization of seed oil from different varieties of watermelon [Citrullus lanatus (Thunb.)] from Paskistan. Grasas $Y$ Aceites, 63(4): 365-372. DOI: http://dx.doi.org/10.3989/gya.022212

Shahidi F, Wanasundara WN. 1998. Omega- 3 fatty acid concentrates: nutritional aspects and production technologies. Trends Food Sci. Technol., 9: 230-240.

Sonntag NOV. 2000. Erucic and behenic: feedstock of the $21^{\text {st }}$ century. Inform., 2(5): 449-463.

Tidbury GE, Gaener RJ, Chuadhary SA. 1976. Averrhoa spp-carambola and Bilimbi. In The Propagation of Tropical Trees. FAO: London; 291-230.

Tilak RM, Tukaram A, Brij ML, Valangaman, SS. 2006. A study of seeds of musk melon (Cucumis melo L.), A lesser known source of edible oil. J. Sci. Food Agri., 10: 973-978. DOI: http://dx.doi.org/10.1016/jsfa.2005.04.0 07
Traitler H, Willie HJ, Studer A. 1998. Fractionation of blackcurrant seed oil. J. Am. Oil Chem. Soc., 65(5): 755-760. DOI: http://dx.doi.org/10.1021/ jacs.1998.06.009

Vasconcelos IM, Siebra EA, Maia AAB, Moriena RA, Neto AF, Compelo GJA. 1997. Composition, toxic and antinutritional factors of newly developed cultivars of Brazillian soybean (Glycine max.). J. Sci. Food Agric., 75: 419-426. DOI: http://dx.doi.org/10.1002/jsfa.7601

Yung SH, Suzettee LP, Amanda EI. 2004. Enzyme for transgenic biosynthesis of long chain polyunsaturated fatty acids. Biochem., 86: 793-798. DOI: http://dx.doi.org/10.1021/bio.2003.03.0 12

Ziyada AK, Elhussien SA. 2008. Physical and chemical characteristics of Citrullus lanatus Var. Colocynthoide seed oil. J. Phy. Sci., 19: 69-75. DOI: http://dx.doi.org/10.5897/ijps.2008.04.0 10 